\title{
Newborn Apnea Caused by a Neurofibroma at the Craniocervical Junction
}

\author{
David B. Clarke, Jean-Pierre Farmer, José L. Montes, Gordon V. Watters \\ and Guy Rouleau
}

\begin{abstract}
The authors report, for the first time, the finding by magnetic resonance imaging of a neurofibroma at the craniocervical junction with upper cervical cord and lower brainstem compression causing complete apnea from birth. Subsequent subtotal resection of the neurofibroma resulted in the successful extubation of a previously ventilator-dependent patient. After a two month period of breathing spontaneously, the newborn developed an upper respiratory tract infection and was reintubated. The patient, unable to be weaned off of the respirator, was extubated and expired shortly thereafter, at the age of five months. The authors suggest that in newborns with unexplained apnea, MRI of the craniocervical junction is indicated. Certain patients may be discovered who have less compromised cervicomedullary function and are afflicted by less aggressive forms of neurofibromatosis type 1 . These patients may benefit permanently from a surgical decompression.
\end{abstract}

Résumé: Apnée du nouveau-né causée par un neurofibrome de la jonction craniocervicale. Nous décrivons, chez un bébé démontrant une apnée complète depuis la naissance, la présence à l'imagerie par résonance magnétique, d'un neurofibrome craniocervical comprimant la jonction cervicomédullaire. Une décompression chirurgicale radicale mais incomplète a provoqué un retour de la respiration spontanée pour une période de deux mois. Cependant, suite à une infection respiratoire, la patiente a dû être réintubée et ventilée, et n'a pu être sevrée du respirateur par la suite. Nous croyons qu'il est important de procéder à l'imagerie par résonance magnétique chez le nourrisson prisentant une apnée complète. Chez certains patients porteurs d'une tumeur moins agressive, une cure permanente pourrait être envisagée.

Can. J. Neurol. Sci. 1994; $21: 64-66$

Newborn apnea occurs for a variety of reasons, including severe acidosis, asphyxia, fetal infections, maternal drug administration, airway obstruction, cardiovascular compromise, and central nervous system damage. The well-described central nervous system disorders causing perinatal respiratory difficulties include intracranial hemorrhage, seizures, bilirubin encephalopathy, and central hypoventilation. In addition to an idiopathic group, various causes of central hypoventilation have been identified and include posterior fossa tumors, the Arnold Chiari malformation, encephalitis, severe asphyxia, high cervical cord trauma, medullary infarction, and inborn errors of metabolism. ${ }^{1.4}$

The authors describe a term baby who was apneic at birth and they report, for the first time, the finding by magnetic resonance imaging (MRI) of a neurofibroma at the craniocervical junction causing upper cervical cord and lower brainstem compression. After surgical resection of the tumor, the newborn initiated spontaneous respirations and was later extubated.

\section{Case History}

The patient was a female, born to a thirty-five-year-old $G_{3} P_{2} A_{1}$ Philippine mother by spontaneous vaginal delivery. The mother was found to have neurofibromatosis type 1 (NFl) after the birth of her first child, a boy who also has NFI. The pregnancy with the patient was uneventful, as was the delivery, which occurred rapidly after spontaneous rupture of the membranes. The baby's skin was noted to be a dusky colour at birth and the baby neither cried nor made any respiratory effort. She was immediately given ventilatory support and, at thirty minutes of life, intubated. The Apgar scores were 5 and 7, at 1 and 5 minutes respectively. The birth weight was $3050 \mathrm{~g}$, and the head circumference $32 \mathrm{~cm}$. The patient was transferred to the Montreal Children's Hospital at seven hours of age for investigation of respiratory failure.

On examination, the patient was intubated and there was no spontaneous respiratory effort. There were no dysmorphic features. The general examination was remarkable only for a hyperpigmented patch of skin over the anterior base of the neck and anterior chest wall. The neurological examination showed a baby that was very awake and active. The pupils were equal and facial grimacing was symmetrical. The gag reflex was present but diminished. She moved all four limbs

From the Division of Neurosurgery (D.B.C., J.P.F., J.L.M.), Department of Neurology (G.V.W., G.R.), The Montreal Children's Hospital, McGill University. Montreal. RECEIVED MAY 20, 1993. ACCEPTED IN FINAL FORM SEPTEMBER 22, 1993.

Reprim request to: Jean-Pierre Farmer, M.D., Division of Neurosurgery, The Montrea Children's Hospital, McGill University, 2300 Tupper Street, Montreal, Quebec. Canada H3H IP3 
symmetrically. Tone was normal in the upper extremities and somewhat diminished in the legs. Reflexes were remarkable for mild hyperreflexia over the left hemibody.

The patient was admitted to the neonatal intensive care unit and remained on completc ventilatory support. Investigation of the respiratory failure suggested a central cause. Electroencephalography was within normal limits. Head ultrasound was unremarkable and computerized tomography (CT) of the head showed some evidence of cortical dysplastic changes but did not reveal a lesion which could explain the apnea. Because of the clinical suspicion of a brainstem lesion, magnetic resonance imaging (MRI) of the brain and craniocervical junction was performed. This showed an extradural/intradural lesion consistent with a neurofibroma, extending from the foramen magnum to the $\mathrm{C} 7$ level inferiorly, encasing circumferentially the cervicomedullary junction (Figure 1).

Since compression of the brainstem by the lesion at the craniocervical junction could cause the infant's lack of respiratory drive, an attempt was made at surgical decompression. Preoperative vertebral angiogram showed no vascular blush. At four-and-one-half weeks of age, the patient underwent resection of the tumor. The intradural resection was complete but the extradural resection was subtotal ( $85 \%)$, as intraoperative difficulties with ventilation had led to the premature termination of the operation.

As the operative anesthetic wore off, the patient began to make respiratory efforts for the first time. The initial postoperative course was stormy, marked by blood pressure and heart rate fluctuations, hyponatremia and temperature instability, all of which were attributed to a small, right hypothalamic hemorrhage documented on CT scan. These difficulties resolved and the patient's respiratory status improved, with good spontaneous respiratory effort seen when the $\mathrm{pCO}$, was allowed to rise to greater than $50 \mathrm{mmHg}$. At the age of two months the baby was extubated. She was subsequently transferred from the intensive care unit at the age of two months, awake, alert, moving all four limbs, and feeding well.

An elective MRI was done approximately one month later. It showed, as expected, residual tumor. The child maintained spontaneous respiration with $\mathrm{pCO}_{2}$ values ranging from 60 to $70 \mathrm{mmHg}$. The presence of tachypnea was evidence that there was respiratory drive; this respiratory drive, however, may have been inadequate and/or her mechanical effector mechanism compromised resulting in ineffective ventilation. She deteriorated at the time of an upper respiratory infection and required reintubation. She was taken to the operating room for completion of the resection and this was uneventful. Because of shifting atelectasis and poor respiratory drive, however, she failed to respond to weaning procedures and remained intubated. A follow-up C.T. scan of the head showed ventriculomegaly suggestive of hydrocephalus, resulting from fourth ventricular outflow obstruction secondary to tumor, and a shunt was inserted. Despite demonstration of intracranial hypertension intraoperatively and resolution of ventriculomegaly post-operatively, the patient could not be weaned off the respirator. After consultation with the family and the hospital ethics representative, the patient was extubated, at five months of age, and expired shortly thereafter. Post mortem examination was refused by the family.

\section{Discussion}

The addition of MRI to the radiologic armamentarium has revolutionized the fields of neurology and neurosurgery. The anatomic detail revealed by MRI in the previously difficult-toimage area of the craniocervical junction, in combination with MRI's noninvasiveness, has allowed rapid and exquisite confirmation of a diagnostic suspicion. Furthermore, improved microneurosurgical techniques such as the operating microscope, the laser, and the cavitron, ${ }^{2}$ utilized in the milieu of improved anesthetic conditions, have all contributed to making the craniocervical junction an accessible area for therapeutic intervention.

The observation that craniocervical junction pathology may be implicated in respiratory difficulties is not new. In the Arnold Chiari malformation, hypoventilation secondary to medullary
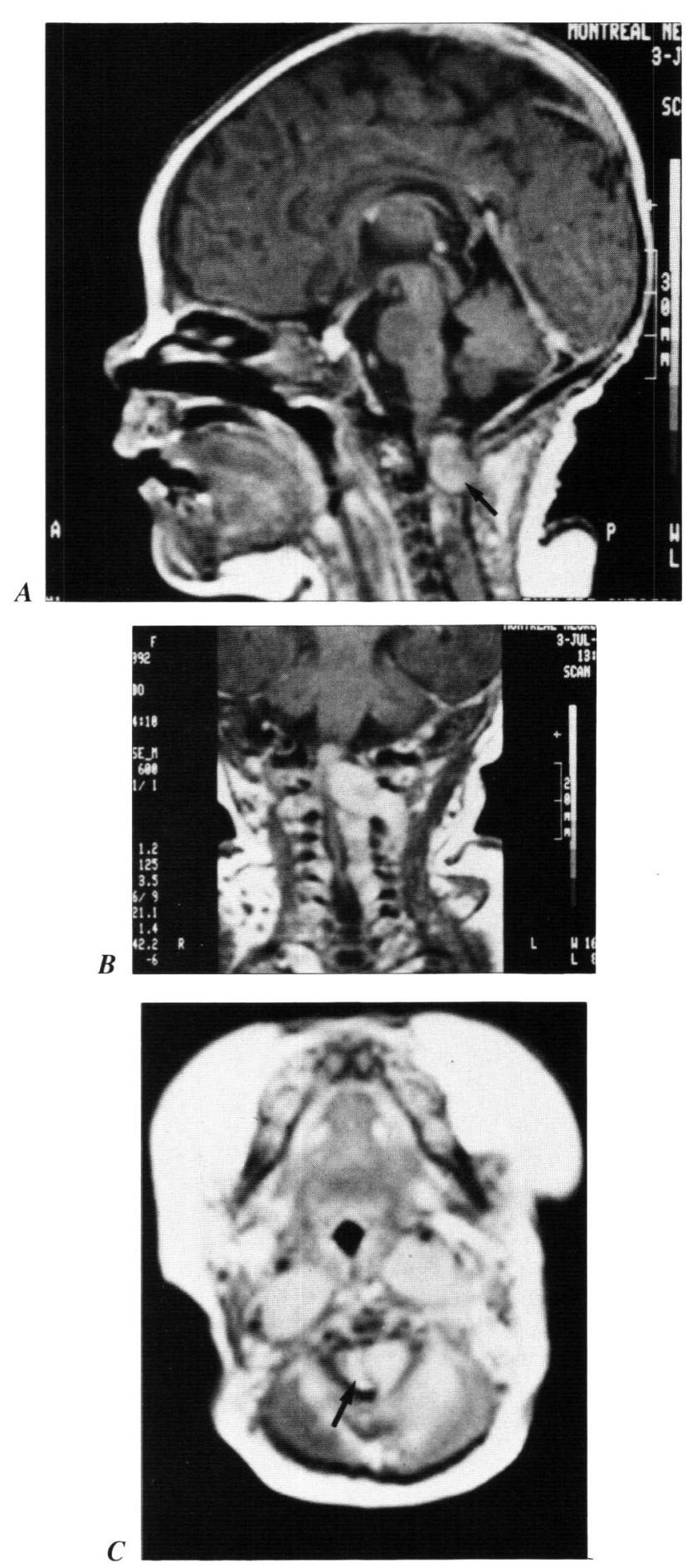

Figure 1: TI weighted MRI (with gadolinium injection) of the craniocervical region. A) Mid-sagittal view show's posterior compression of the lower medulla by tumor (arrow) at the level of the foramen magnum. B) Coronal view show's a large intradurallextradural left-sided tumor at $C$, with plexiform extension within the vertebral canal inferiorly to $C_{7}$. C) Axial view demonstrates a crescentic deformity of the spinal cord (arrow') by the circumferential encasement of the dumbbellshaped lesion.

compression may occur in addition to paralysis of the vocal cords due to bulbar palsy. ${ }^{3}$ In addition, compromised ventilation has been noted in infants with achondroplasia due to medullary compression associated with narrowing of the foramen magnum. ${ }^{5}$ 
Neurofibromatosis has also been associated with respiratory embarrassment. A number of cases of plexiform neurofibroma of the larynx causing obstructive sleep apnea, for example, have been reported. ${ }^{6}$ Neurofibromatosis hyperkyphosis, with resulting respiratory compromise, has also been described.?

This particular patient was afflicted by an unusually aggressive form of NF1, as evidenced by the tumor size, its presence at birth, and the severity of the clinical presentation. The MRIdocumented craniocervical neurofibroma caused complete central apnea from birth. It was not until surgical decompression of the craniomedullary junction facilitated return of the respiratory drive that the patient began to make respiratory efforts and could be extubated. The aggressive nature of her disease, coupled with the likely long-standing prenatal cervicomedullary compression, was associated with irreversible damage and left the patient incapable of maintaining spontaneous respiration for more than a few weeks. Aggressive management was instituted in light of an initial good response to a subtotal decompression.

In the case presented, the MRI detection and subsequent neurosurgical resection of the craniocervical junction neurofibroma resulted in the successful extubation of a previously ventilator-dependent patient. The authors suggest, therefore, that in newborns with unexplained apnea, MRI of the craniocervical junction is indicated. Patients with a less compromised cervicomedullary function or afflicted by a less aggressive form of NF1 may benefit in a permanent fashion from surgical decompression.

\section{REFERENCES}

1. Brady JP and Brooks JG. Abnormalities of control of respiration. In: Rudolph MR, Hoffman JIE, eds. Pediatrics. Norwalk, Connecticut: Appleton and Lange, 1987: 1376-1380.

2. Epstein FJ and Farmer JP. Trends in surgery: laser surgery, use of cavitron and debulking surgery. Neurol Clin North Am 1991; 9.2: $307-316$

3. Camfield P, Camfield C, Bagnell P, and Rees E. Infant apnea syndrome: a prospective evaluation of etiologies. Clin Pediatr $1982 ; 21: 684$.

4. Johnston K, Newth CJ, Sheu KF, et al. Central hypoventilation syndrome in pyruvate dehydrogenase complex deficiency. Pediatrics 1984; 74: 1034.

5. Pauli RM, Scott CI, Wassman ER Jr, et al. Apnea and sudden unexpected death in infants with achondroplasia. J Pediatr 1984; 104: 342.

6. Sidman J, Wood RE, Poole M, and Postma DS. Management of plexiform neurofibroma of the larynx. Ann Otol Rhinol Laryngol 1987; 1: 53-55.

7. Winter RB, Lonstein JE, and Anderson M. Neurofibromatosis hyperkyphosis: a review of 33 patients with kyphosis of 80 degrees or greater. J Spinal Disord 1988; 1: 39-49. 